\title{
LEGISLATIVE ACCOUNTABILITY: SHOULD BRAZIL BREAK UP ITS BIG ELECTORAL DISTRICTS?
}

\section{ACCOUNTABILITY LEGISLATIVA: O BRASIL DEVERIA FRAGMENTAR SUAS CIRCUNSCRIÇÕES ELEITORAIS MAIORES?}

\author{
John M. Carey ${ }^{* 1}$
}

\begin{abstract}
This paper proposes that Brazil could improve the political accountability by breaking up many of the statewide districts it uses to elect its deputies into smaller districts, each electing fewer deputies. The central argument is that districts that elect low-to-moderate numbers of legislators make it possible to optimize the well-known trade-off between inclusive representation and accountable government. I suggest there are three broad goals that we should seek in legislative representation; representativeness, collective accountability, and Individual accountability. I acknowledge that there are inevitable trade-offs among these goals, but I suggest that the trade-offs are not linear, and that electoral rules can be designed to maximize the quality of representation. I suggest that the most straightforward way to achieve such gains is by maintaining proportional representation systems of elections, but by limiting district magnitude (the number of representatives elected per district) to moderate levels, in the range from 4 to 8 .
\end{abstract}

Keywords: Elections; Election Rules; Electoral Systems; Electoral Reform; Accountability; Representation.

Resumo: Este trabalho propõe que o Brasil é capaz de aperfeiçoar sua responsividade ou accountability política por meio da fragmentação de muitas de suas circunscrições estaduais que utiliza para eleger deputados, em distritos menores, cada qual elegendo um número menor de deputados. O argumento central é que distritos que elegem um número de parlamentares de baixo para moderado possibilita a otimização da conhecida troca ou trade-off entre um representação inclusiva e um governo responsivo ou accountable. Sugiro que existem três grandes alvos que se deveriam alcançar na representação parlamentar: representatividade, responsividade ou accountability coletiva e responsividade ou accountability individual.

\footnotetext{
${ }^{*} \mathrm{PhD}$ in Political Science from the University of California, San Diego, USA. He is currently Professor of Comparative Politics at Dartmouth College, USA. Areas of research: studies of constitutions, legislature, elections and Latin American politics (john.carey@dartmouth.edu).

${ }^{1}$ I want to thank all the organizers of the Third International Seminar on the Legislature, and in particular Julio Roberto de Souza Pinto, for his hard work, making it possible for me to be there.
} 
Reconheço a existência de trocas ou trade-offs inevitáveis entre esses alvos, mas sugiro que essas trocas ou trade-offs não são lineares, e que as regras eleitorais podem ser maximizadas de maneira a qualificar a representação. Sugiro que a maneira mais simples de conseguir isso é mantendo o sistema eleitoral proporcional, mas reduzindo a magnitude eleitoral (número de eleitos por distrito) a níveis moderados, que variem de 4 a 8 .

Palavras-Chave: Eleições; Regras Eleitorais; Sistemas Eleitorais; Reforma Política; Accountability; Representação.

\section{Introduction}

I am going to start by raising a question, and then most of my comments today will be an effort to explain why I am asking it. The question is: Should Brazil break up the districts it uses to elect its legislators? Specifically, I am referring to the statewide districts used to elect members of the Chamber of Deputies. Most deputies in the Chamber are elected from districts with what I will call "high magnitude," where district magnitude (DM) refers to the number of legislators elected in a given district (not to its geographical size). I regard districts that elect more than ten legislators as high-magnitude districts. By this standard, more than three-quarters of Brazil's deputies are elected from high-magnitude districts. So my specific question is whether Brazil should consider sub-dividing its states to create a larger number of districts with lower magnitudes - that is, with fewer deputies elected from each one.

I want to acknowledge at the outset that I am not a specialist in Brazilian politics. I have visited Brazil only once before - much too briefly - and as you can see, I do not speak Portuguese. I read the work of my colleagues in political science on Brazil, and I find the country fascinating, but I have done little research of my own on Brazil, and I admit that I do not know whether this question I am raising is new, or whether it has already been subject to debate. So I most certainly do not claim any particular expertise on the unique context of Brazilian elections.

Instead, my question is motivated by patterns that evident in my own research across a variety of countries, and how these patterns relate to broad principles of representation. Specifically, it is motivated by two claims that I will discuss in my comments here:

1. That low-to-moderate magnitude districts make it possible to optimize the wellknown trade-off between inclusive representation and accountable government.

2. That accountability of individual legislators to their voters is possible in lowmagnitude districts.

Before I advance these claims, I also want to establish clearly what are the normative ideals of representation I care about. Most of my academic research focuses on the question of whether it is possible to improve representation in democracies through the design or reform of 
the formal rules of political competition - for example how representatives are elected, or how legislatures and executives interact to make policy. The question I raise today involves elections, and specifically, I am interested in what we want from legislative representation. I suggest there are three broad goals that we should seek:

- Representativeness

- Collective accountability

- Individual accountability

Representativeness: Legislatures aim to reflect the diversity of societies, so one priority should be inclusiveness. The results of elections should accurately reflect the diversity of preferences in the society. This means that parties with substantial voter support should win representation, and that there should be a strong correspondence between the level of support a party wins and its share of legislative seats.

Collective accountability: By this, I mean that collective labels under which groups of candidates run for election should have substantive meaning that voters can attach to policy outcomes, and that voters can reward or punish parties or coalitions for the performance of governments in which they participate. So collective accountability is undermined if, for example, the number of parties in government is so large that responsibility is impossible to determine, or if legislators from the same party are no more likely to support the same policies than legislators from different parties. Collective accountability means that elections provide meaningful 'brand names' that voters can attach to parties in government and in opposition.

Individual accountability: By this, I mean that individual legislators can be rewarded or punished by voters according to their performance. Voters might want to base such decisions on performance related to policy - say, on whether a legislator supported specific piece of legislation on the distribution of natural resource revenues among states. But that basis might also be the level of effort the legislator exerts - for example, whether she is absent for votes and committee meetings - or whether there are credible allegations that she engages in corruption. By whatever criteria voters choose to evaluate their representatives, individual accountability requires that elections allow them a means to render judgments on candidates, independently from their collective judgment on parties.

\section{The Representation-Accountability Trade-Off}

So if the goal of legislative elections is to produce some combination of representativeness, collective accountability, and individual accountability, then the first thing that most observers will of elections around the world will tell you is that you cannot have all three things at once - that there are inevitable trade-offs among them.

In particular, there is a long tradition in the scholarship on comparative democracy that contends that there is a straightforward trade-off between representativeness and collective 
accountability. The argument is familiar, so I will not rehearse it in detail here, but the standard version contends that majoritarian elections deliver single-party governing majorities. They may do this by severely distorting the correspondence between vote shares and seat shares, usually by awarding a large "winner's bonus" to the largest party - thus undermining accurate representation - but such outcomes make responsibility for governing outcomes clear, and thereby facilitate collective accountability. By contrast pure proportional representation systems are said to guarantee good correspondence between vote shares and seat shares, but in doing so they often yield highly fragmented party systems. These systems may be inclusive of society's diversity, and therefore strong on representation, but voters have difficulty assigning responsibility for policy outcomes, making collective accountability weak.

The standard account contrasts, as archetypes, countries that conduct their elections in single-member, winner-take-all districts (such as Australia, the United Kingdom, and the United States) against countries that rely on high-magnitude districts which elect scores of representatives, thus guaranteeing high vote-seat correspondence (such as Israel, the Netherlands, Uruguay -- and Brazil). The implication of such arguments is generally that the trade-off faced by those designing electoral systems is linear - that if you want more representation, you must sacrifice an equal measure of collective accountability, and vice-versa, as illustrated by the line connecting the two axes in Figure 1.

\section{Two Versions of the Trade-Off between Accountability and Representation in the Design of Electoral Systems}

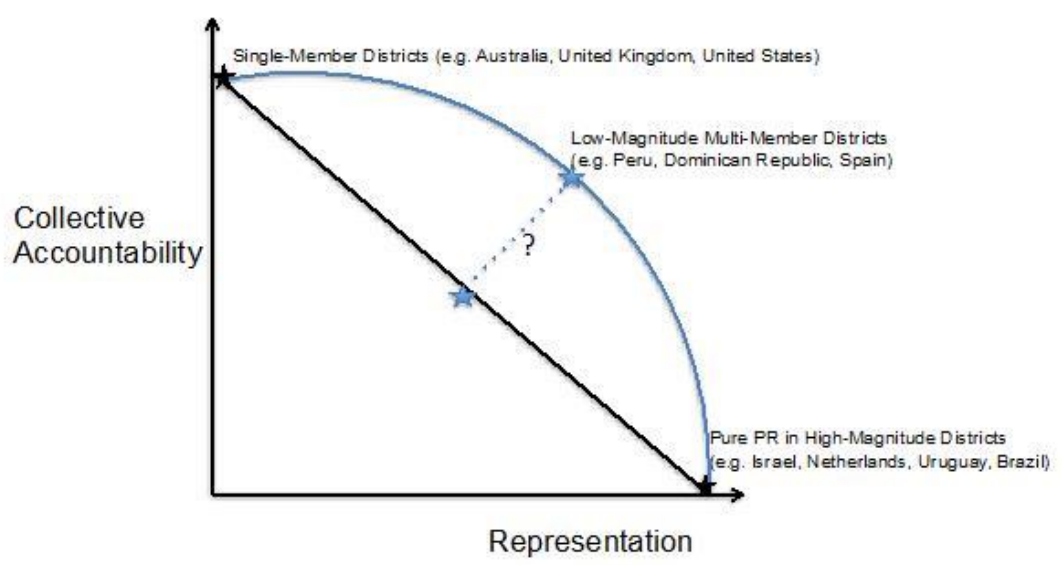

Figure 1: Accountability and Representation in the Design of Electoral Systems

By contrast, although I acknowledge that there is a trade-off between collective accountability and representation, I want to suggest that the trade-off is not linear, but is better represented by the arc in Figure 1, which suggests that electoral systems can be designed to 
achieve locations on the accountability-representation frontier that achieve gains on one dimension that may outweigh the sacrifices on the other. Moreover, I want to suggest that the most straightforward way to achieve such gains is by maintaining proportional representation systems of elections, but by limiting DM to moderate levels, which I would characterize as in the range from 4 to 8 .

In collaboration with Professor Simon Hix, of the London School of Economics, I conducted a statistical analysis of the effect of DM on a series of electoral outcomes that we associated with good representation. As indicators of Representativeness, we measured:

- Vote-Seat Correspondence, or the degree to which each party's seat share in the lower legislative chamber reflected its overall support among voters.

- Voter-Government Correspondence, or the degree to which the ideological position of the governing party (or parties) corresponded to the ideological center of gravity among citizens.

As indicators of Collective Accountability, we measured:

- Party System Simplicity, an index of party system fragmentation in the legislature.

- Simplicity of Governing Coalitions, or the number of parties holding cabinet portfolios.

We examined the results of 609 elections - every election that met our standards as free and fair - in 81 countries between 1945 and 2006, and we found, as we expected, that the likelihood of Vote-Seat Correspondence and of Voter-Government Correspondence both rise as DM rises, and that the likelihood of Simple Party Systems and Simple Governing Coalitions both decline as DM rises. This is as expected - higher DM elections encourage Representativeness and discourage Collective Accountability.

The key result from our study, however, is that these relationships are subject to varying rates of diminishing returns. That is, you can capture almost all the available gains in Representativeness by moving from single-member district (SMD) elections to DM of around 5 to 7 . Moving from 7 up to 20 , or to 50 , or 200 provides relatively little additional gain. By contrast, our measures of Collective Accountability, Simple Party Systems and Government Coalitions, electoral outcomes decline a bit less precipitously with DM. 


\section{District M agnitude and the Probability of Favorable Outcomes}

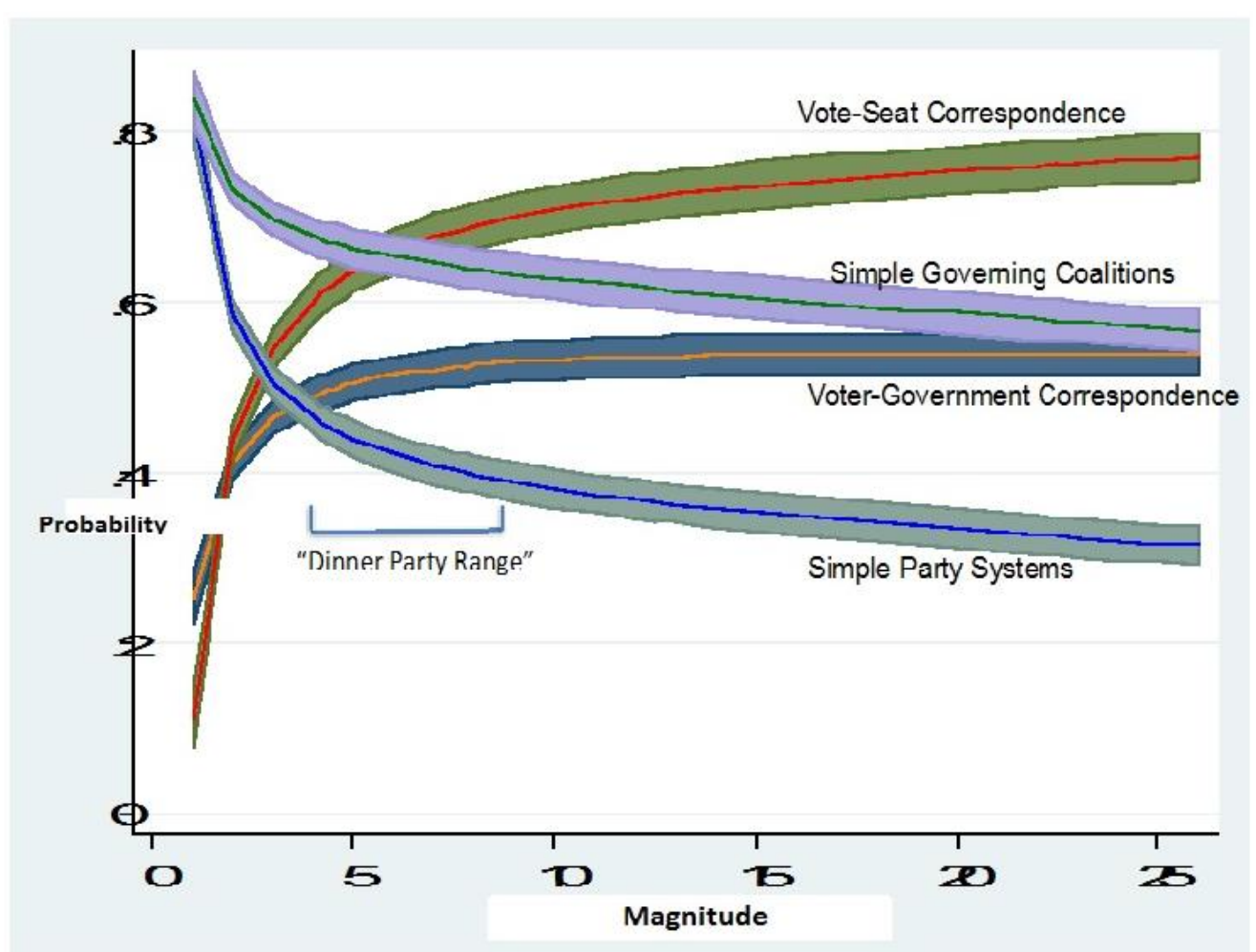

Figure 2 - District Magnitude and the Probability of Favorable Outcomes

Figure 2 shows the likelihood of better-than-average outcomes on each of our four metrics as a country's average DM rises from 1 to 25 . What is clear from the graph is that one can reap almost all the expected gains on the Representativeness metrics, while also preserving good expected outcomes on the Collective Accountability metrics, with DM in the low-tomoderate range - between 4 and 8 .

Hix and I label these values of DM the "dinner party range" because, as it happens, experts on etiquette recommend that, when hosting a dinner party, the ideal number of guests is 4 to 8 . Below this number, and the conversation may stagnate. Above it, and too many voices may make it impossible to maintain a single conversation. I mention these rules of etiquette only half in jest, because the logic of the dinner party applies to political debate and competition. Inclusive representation demands that sufficient voices must be included, but too many voices may produce cacophony from which voters cannot distinguish any coherent policy platforms.

To sum up and remind the audience, my first claim is that low-to-moderate magnitude districts make it possible to optimize the well-known trade-off between inclusive representation and collective accountability. What about the third representative goal that I have outlined, however, individual accountability? 


\section{Individual Accountability}

My second claim is that low-magnitude districts also enhance the accountability of individual legislators to their voters. The idea here is straightforward - that voters have limited cognitive capacity, and that limiting DM encourages a closer correspondence between the electoral options presented to voters and the number of alternative among which they can meaningfully distinguish.

In 1956, in one of the most famous and widely cited studies ever published in cognitive psychology, entitled "The Magic Number Seven," George Miller demonstrated that humans are capable of distinguishing clearly among a limited set choices along a single dimension, but that the ability to discern differences and establish consistent rank orderings falls off precipitously when the number of alternatives rises above the seven to nine range. Monitoring and evaluating the performance of individual MPs is clearly simpler for citizens in lower DM districts than in those with higher DM - there are fewer MPs to keep track of. But Miller's results suggest a curvilinear relationship like what we saw with our measures of Representativeness and Collective Accountability, whereby citizen monitoring of individual legislators can be effective where there are fewer than 10 politicians to keep track of, but above that number, the ability to monitor falls off precipitously.

It is important here to note that Brazil's method of electing legislators, open-list proportional representation, allows voters maximum flexibility to reward or punish specific individual politicians with their votes. Unlike in closed-list systems, such as Argentina's, Brazilian voters indicate preference for an individual candidate within a party list, and a candidate must win substantial preference votes to win a seat.

But can Brazilian voters make informed distinctions among the set of choices with which they are presented on election day? Figure 3 shows the number of seats (DM) contested, and the number of candidates on the ballots, in each Brazilian state during the 2006 Chamber of Deputy elections. (I have not collected analogous data for the 2010 election, or for other years, but I expect they would be similar.) In the least populated states, with $\mathrm{DM}=8$, and those with DM close to that range, the number of candidates was generally below 100. But as DM rose toward 20, the number of candidates grew above 200. Voters in Rio de Janeiro, with DM=46, faced over 700 candidates. Voters in Sao Paolo, with 70 seats, faced more than 1,000. 


\section{How many options is too many?}

M and \# Candidates, by district, Brazil Chamber Elections, 2006

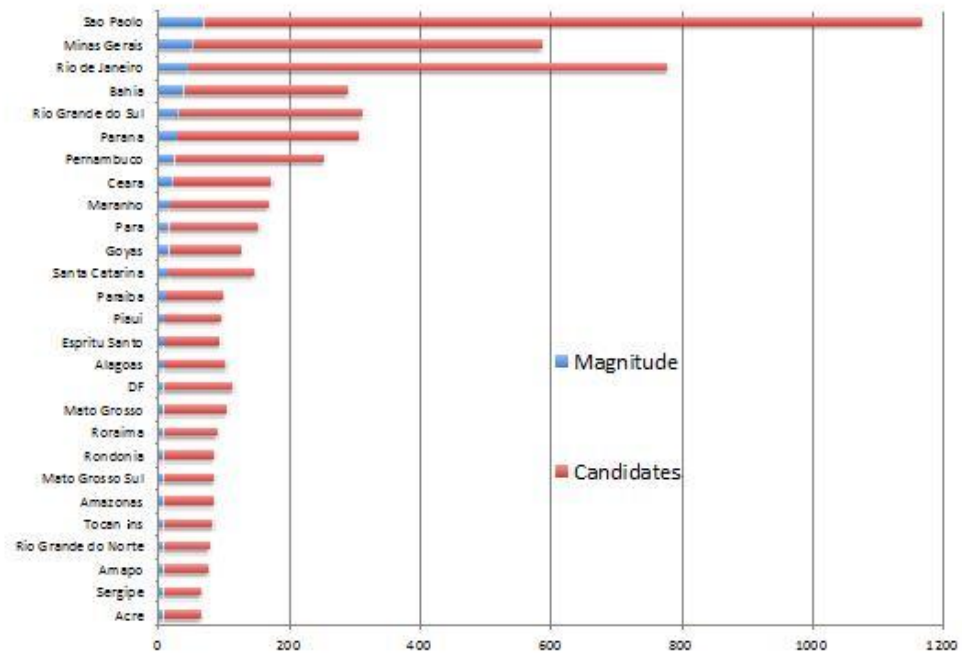

Figure 3: Magnitude and Candidates, by District, Brazil Chamber Elections, 2006

Granted, the raw numbers may not be relevant in a literal sense. No Sao Paolo voter necessarily needed to have a fully informed opinion on each of the 1,098 candidates in that state to cast a meaningful ballot. Yet even within that voter's most-preferred party, the list could have included over 100 candidates. At the least, we can say that the deluge of candidates confronting voters in most Brazilian states is positively correlated with DM, and in most states, monitoring and selecting among the alternatives would strain the cognitive capacity of any voter.

But would things be different in smaller districts? Can individual accountability operate effectively in an environment with fewer representatives? Here, I want to bring some data from both the real world of politics, and from the experimental world of the laboratory to bear. In both instances, my point is that individual accountability is possible where the actions of representatives are transparent to citizens.

The first question is whether legislators' actions are, in fact, visible to citizens. It is not obvious how to answer this question in a way that is comparable across countries. Some legislative activity is visible everywhere (for better or worse), but no citizen has the need - or the interest - to know about all his representative's activities. I chose to measure the number of votes from the floor (plenary) of the assembly that are recorded at the level of individual legislators and published each year. I chose this metric because votes are the common currency of decision-making in all legislatures. I regard a visible vote as one that takes place on the floor of the legislative chamber, and on which the vote of each legislator (Aye, Nay, Abstain, Absent, etc.) is made public.

Figure 4 shows the number of Visible Votes my research assistants and I were able to 
find from each calendar year during recent decades, in a number of South American countries that employ electronic voting machines in their legislatures. The figures for the Brazilian Chamber and the Senate are shown in the solid lines, whereas the figures for Argentina, Chile, and Peru are shown in dashed lines. In recent years, the Brazilian Chamber and Senate have both published between 100-200 visible votes in most years - not as many as their Chilean counterparts, but more than the Chamber in Argentina or the Peruvian Congress.

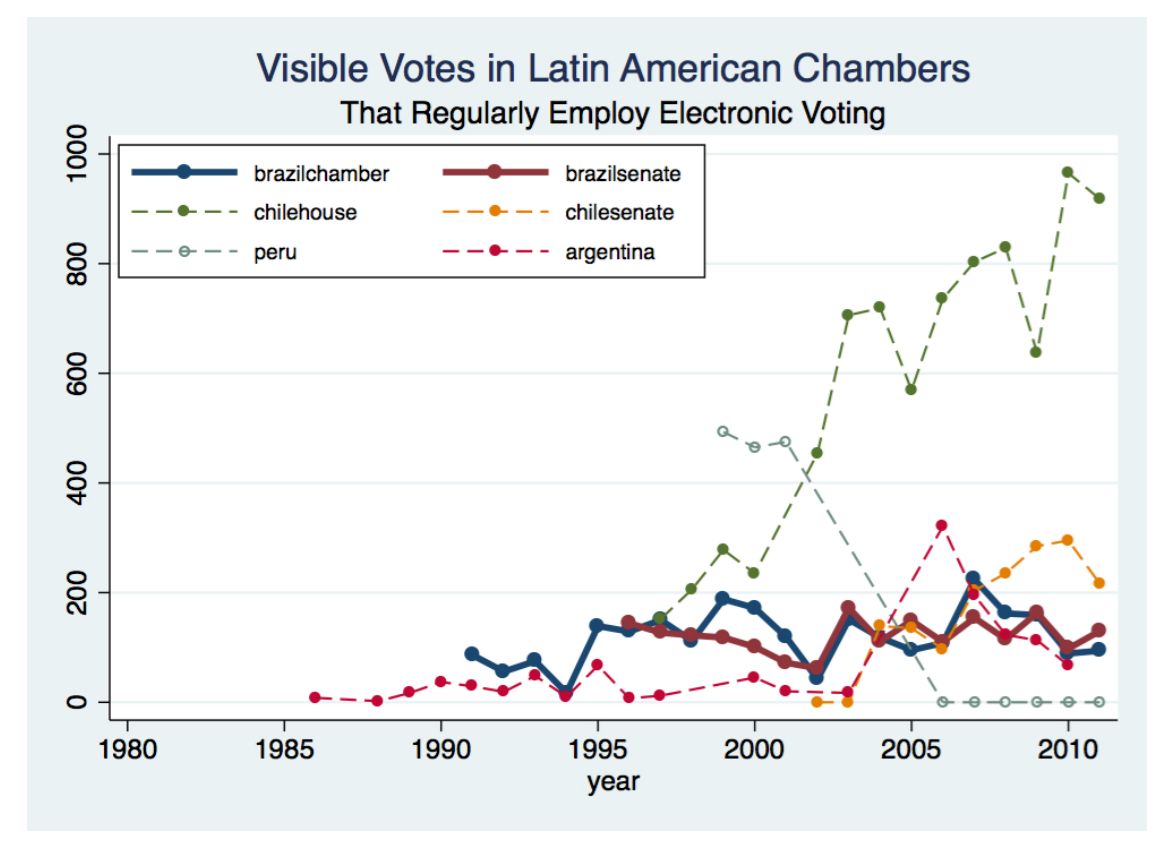

Figure 4: Visible Votes in Latin American Chambers

Note however, that all these chambers with electronic voting equipment far surpass the number of visible votes produced in legislatures that lack such technology. Figure 5 shows analogous rates of visible voting for a larger number of Latin American assemblies that do not employ electronic voting equipment as standard operating procedure. Note that the scale of the $\mathrm{Y}$-axis is tiny as compared with the previous figure. Where voting is done manually, individual-level records are almost never produced, and individual legislators' votes - on issues that affect citizens' lives in profound ways - are almost uniformly not visible to voters. 


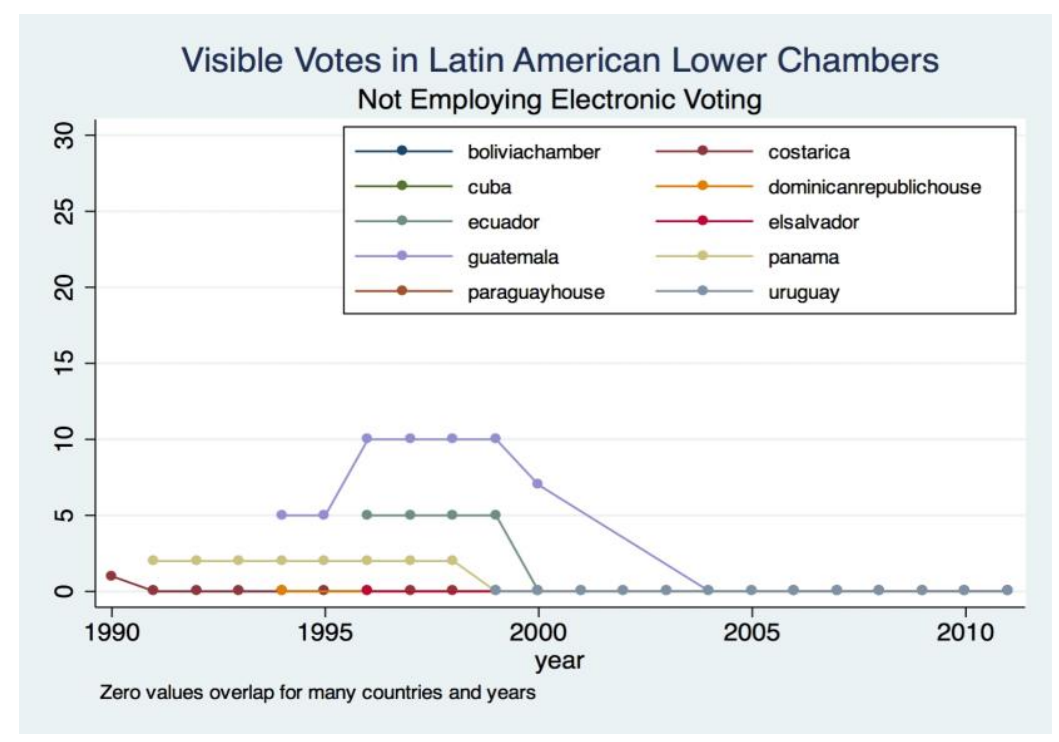

Figure 5: Visible Votes in Latin American Lower Chambers

What difference does it make if votes are visible? This is something that is extremely difficult to determine on the basis of traditional, "observational" studies - relying on information that can be observed in the real world of politics all around us. By definition, we cannot compare legislative behavior or decisions that are never recorded or publicized with those that are. To get some leverage on this question, then, I have been conducting a series of experiments that approximate an extremely simplified legislative environment, but with the advantage that the experiment varies the level of legislative transparency, to allow us to measure whether and how transparency might matter.

The experiment is a repeated game in which participants are assigned roles either as Legislators or as the Public (that is, citizens). Each period of the game involves:

- the division of a budget and its proposal to the Legislators;

- a vote on the budget by the Legislators;

- the revelation to the Public of information about the budget outcome; and

- reward or punishment by the Public of the Legislators.

Participants were paid with actual currency, according to their shares of the budgets proposed and approved. When budget proposals were rejected by the majority of Legislators, the corresponding funds were lost to participants.

The experimental treatments manipulate what information regarding the identity of the proposer, the nature of the proposal, and the legislators' votes are visible to the Public.

The experiment creates 3 different transparency conditions in which the Public observes: 
NT: Non-Transparency

- only its own payout.

\section{ST: Semi-Transparency}

- own payout; and

- the identity of the Proposer

FT: Full Transparency

- own payout;

- the identity of the Proposer;

- how much the proposed budget offered to each Legislator; and

- how each Legislator voted (Approve/Reject) on the budget proposal.

Full transparency mirrors the availability of information in legislatures where voting is visible at the individual level, and published voting records expose every legislator to pressures from actors outside the legislative chamber. Semi-transparency is analogous to legislative decision-making without the comprehensive transmission of voting records, but in the presence of effective legislative parties. That is, even where votes are not recorded and published at the individual level, party leaders generally make their parties' positions known on important proposals before legislatures. In the context of this experiment, for the Public to know its own payoff, and who the proposer was, as under semi-transparency, is akin to knowing which party championed a policy in political system with strong parties. Non-transparency is a closer approximation of the legislative process where the full transmission of information is absent and parties are ineffective, either because they are not the main source policy proposals, or because legislative copartisans do not reliably vote in unison, or both.

Initial runs of the experiment suggest that transparency is good for the Public. The greater the transparency, the higher is the Public's share of the overall budget. There are two mechanisms that encourage this result - what I call first order and second order accountability.

First order accountability operates on the Legislator (chosen at random in these early experiments) who makes the budget proposal. Proposers offered more to the Public when their identity would be revealed to the Public. The effect is visible in the graphs in Figure 6, which show the average budgetary payoffs to each participant, across each period of a 20-period experiment (shown along the X-axis), under Non-Transparency, Semi-Transparency, and Full Transparency, respectively. The Public's payoff is illustrated by the thick, solid line, the Proposer's payoff by the thin, solid line, and the other 2 Legislators' payoffs by the broken lines. 


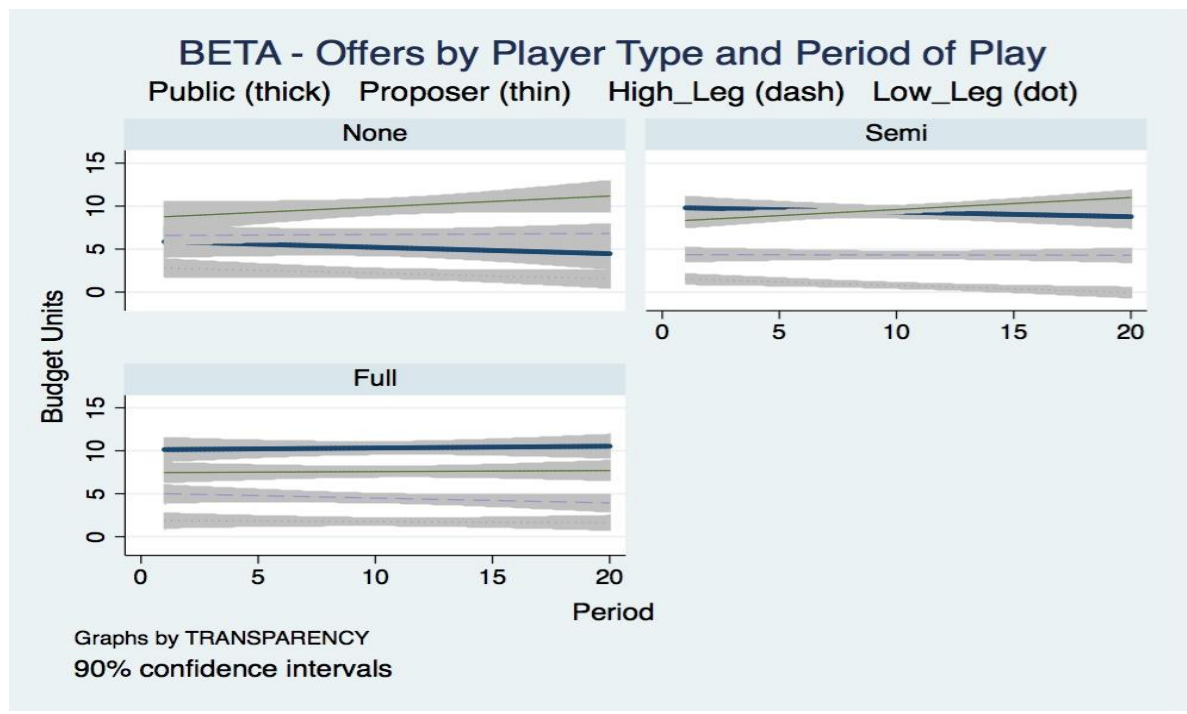

Figure 6: Offers by Player Type and Period of Play

The central lesson from these graphs is that, not only is the Public consistently offered a greater share of budgets when the Proposer's identity will be revealed, but that, under Full Transparency, the trend is favorable to the Public, whereas under Semi- and Non-Transparency, the reverse is the case. That is, as participants in the experiment learned the game - how to monitor, and what kinds of behaviors would be rewarded and punished - the effects of the transparency conditions grew more pronounced, to the Public's benefit under Full Transparency, and to the Public's detriment otherwise.

This effect is reinforced by what I call second-order transparency - which operates not on the Legislator who proposes the budget division, but on the non-Proposers, who also vote to approve the budget or to reject it. Remember, the non-Proposers' votes on the budget are only revealed to the Public under the Full Transparency condition. The question, then, is whether when the information is transparent - the Public effectively monitors the votes of rank-and-file Legislators and rewards or punishes them accordingly. Figure 7 suggests that - at least in my simplified experiment - the Public is capable of doing so. The lines in the graphs represent the probability of the Public rewarding a Legislator, conditional on both how much the Public was offered in a given budget (shown on the X-axis) and whether the Legislator voted to approve or reject that budget. 


\section{Second-order accountability}

Is the Public paying attention?

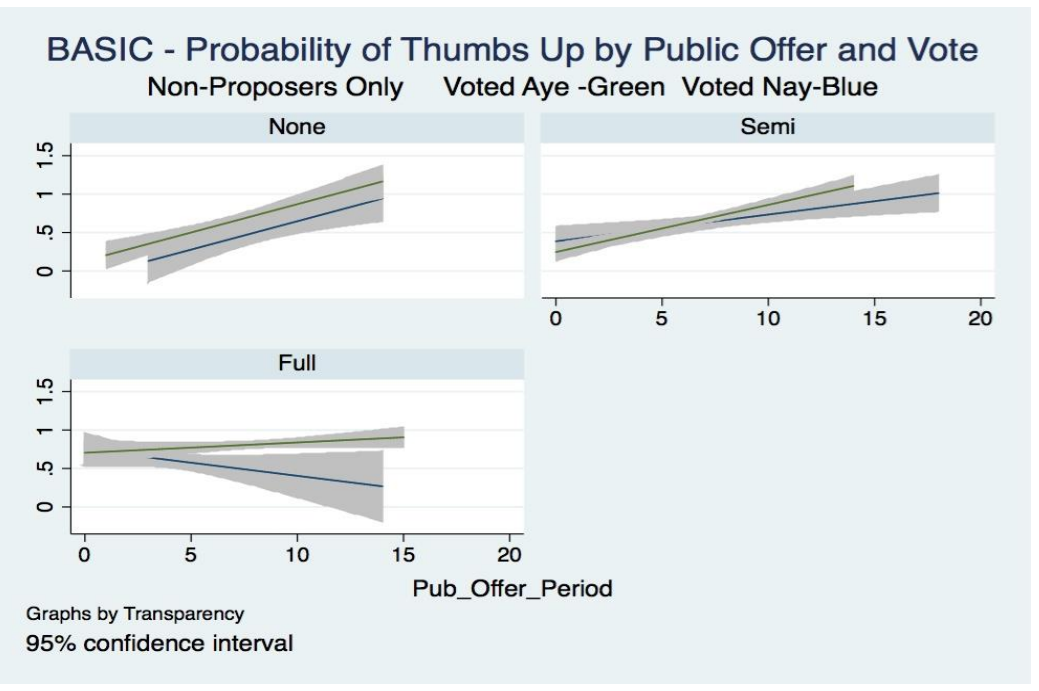

Figure 7: Probability of Thumbs Up by Public Offer and Vote

The top panels of the figure show that, under both Non-Transparency and SemiTransparency, when the votes of the Legislators are not visible, the Public's behavior is simple - the greater its share of the budget, the higher the likelihood of rewarding the Legislators. This is true whether the Legislator in question voted to approve or reject the budget, which is not surprising, given that the Public cannot observe how the Legislators voted. The lower panel shows that, under Full Transparency, when individual votes are visible, the Public makes use of that information. Non-Proposer Legislators are rewarded or punished according to how they voted, conditional on how much the Public was offered. That is, the more the Public was offered, the more likely the Legislator was to be rewarded if she voted to approve. But Legislators who voted to reject a Public-serving budget were punished - and at higher rates, the more generous that budget proposal was.

I want to emphasize that these results are preliminary and incomplete. The experiments have been conducted partly in a laboratory setting (using U.S. university students as subjects) and partly on a web-based platform with a more diverse, and international, participant pool. The format of the game has been varied in subtle, but important, ways that make the results from various experiments difficult to compare with each other. I hope to refine the experiment further, and to produce more reliable results in the future, but even if that is possible, the results will be subject to the same caveat that applies to all experiments - that the immense simplification of the environment and the interactions do not begin to approximate the complexity of the real world.

So there are reasons for skepticism. And all proposals for political reform should be greeted, initially at least, with skepticism. We should always demand evidence, and should only embrace reform when the evidence is compelling. Which leads me to conclude by taking stock, 
once again, of my motivation for raising the question of whether Brazil should break up its state-wide electoral districts in an effort to reduce the average DM. What evidence suggests that this is an idea worth considering?

\section{Summing Up}

The first premise is that the goals of any system for electing legislators should be to balance among three ideals - broad and inclusive representation, collective accountability, and individual accountability. Scholars of representation agree that it is impossible to maximize all three ideals simultaneously. I have presented evidence that the trade-off between the first two is not zero-sum, but rather may be subject to maximization, and that elections in the low-tomoderate range of DM - what Hix and I have labeled the "dinner party range" - perform better at achieving high levels of inclusive representation with relatively simple governing coalitions and party systems - than do elections in pure majoritarian systems, or with proportional representation in high-DM districts.

The favorable effect of low-DM elections on representation and collective accountability also has favorable implications regarding individual accountability. That is, individual accountability is possible under proportional representation systems of election, but only when the voters are allowed to cast preference votes within party lists for individual candidates. However, what we know about voter cognition suggests that candidate preference voting can be exercised most effectively when the number of alternatives that voters confront is not excessive. Preliminary experimental results suggest that, when presented with information about legislators' actions, citizens can effectively monitor them, and administer rewards and punishments in a way that elicits individual accountability.

I would go further, and suggest that key institutional building blocks are already in place in Brazil to encourage a favorable combination of representation with collective and individual accountability. The open-list proportional method of election combines inclusiveness and strong vote-seat correspondence with the preference voting that can foster individual responsiveness. Moreover, Brazil's Congress has in place the physical infrastructure electronic voting, and a well developed web-based system for disseminating voting records that make high levels of transparency possible. The key question is whether, when they vote, Brazilian citizens make use of information about their representatives' performance in the legislature?

Brazilians - including many of you in this room - may have a ready answer to this question, but as I noted at the outset, I am not a specialist in Brazilian elections, and I do not know what that answer is. I do know that, in public opinion surveys that ask respondents throughout Latin America to evaluate their legislators, Brazilians exhibit less than average satisfaction. Figure 8 shows that, in surveys taken last year, in which respondents ranked the 
performance of legislators on a five-point scale, the average satisfaction of Brazilians ranked 12 out of 18 countries.

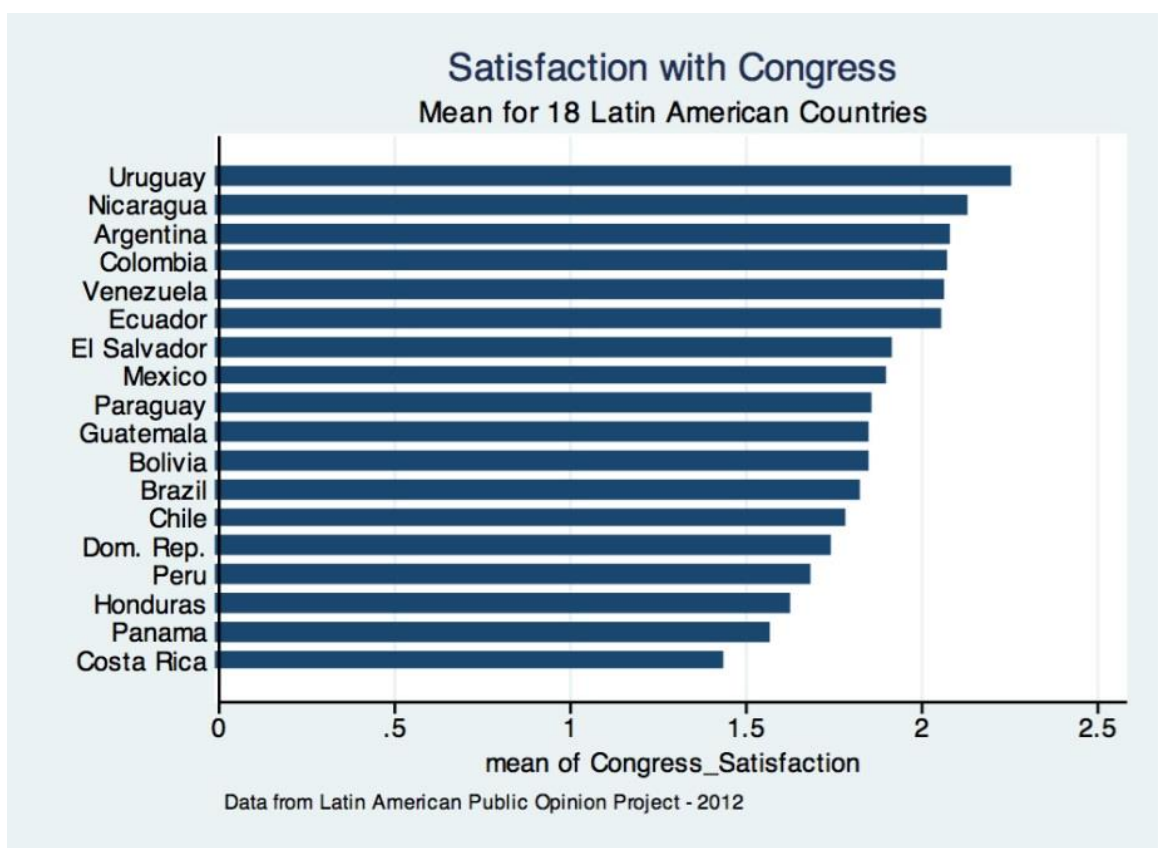

Figure 8: Satisfaction with Congress

I will close, then, by returning to the question with which I started: Should Brazil break up its statewide districts and elect its legislators from somewhat smaller constituencies, particularly in the most populous states, where DM can currently range as high as 70? I ask not because I expect such a reform would fix all of Brazil's representational problems - it would not - but because it may be a reform that could build on some of the strengths already present in Brazilian elections and legislative representation - the presence of candidate preference votes under open-list proportional representation, and relatively high levels of legislative transparency. Thank you for your kind attention to my comments, and I look forward to any response or discussion they might produce. 